\title{
Which book? A comparative review of 25 introductory epidemiology textbooks
}

\author{
Raj Bhopal
}

We are witnessing an epidemic of epidemiology. One outcome is a greater demand for books to meet the needs of an increasingly diverse student body. A widening range of professionals and researchers are discovering the power and fascination of the subject, and their heterogeneity of specialist knowledge and interest poses special challenge. Revisions of classics and many new texts mean difficult choices for teachers and students. The rise of epidemiology will spur new writings so we can anticipate even more.

This review is primarily to help students and teachers to find the first textbook for the keen postgraduate or undergraduate. Practitioners may welcome this as a way of tracking down the book which covers epidemiology in the style they prefer. Aspiring text book writers might see gaps for future work.

I have concentrated on books published since 1980 and in choosing which books to review I was guided by these questions: Might students chose this book as their first textbook? Might teachers recommend this book for general, introductory reading? Is the book attractive to students and teachers on the basis of reputation? Is it already in use as a general text? If yes, my tendency was to review it. Specialist, advanced, and reference works were excluded, especially if the author(s) did not consider the book as introductory. Some books consisting of exercises and meant for self study have been included if they tried to cover the theory and principles too. I hope to have included the main contenders for the first textbook role in English-based courses in epidemiology in the USA and Europe. (Inevitably, some will have been omitted intentionally or unintentionally.)

Department of

Epidemiology and

Public Health, Medical

School, University of

Newcastle Upon Tyne,

Newcastle NE24HH

R Bhopal

Correspondence to:

Professor R Bhopal.

R.S.Bhopal@ncl.ac.uk

Accepted for publication July 1997

\section{Approach}

The books were scanned to assess their purposes, audience, and approach, and then looked at more closely (sometimes selectively, sometimes in full) in relation to seven fundamental issues which I wanted to read about and which I consider to be so important to modern epidemiology that no modern text should omit them:

- The epidemiological way of thinking about:

1. Population, and especially how this differs from demographic and statistical ideas, and the distinction between individual and population causes of disease

2. Causality, and

3. The natural history of disease

- The idea behind and methods of:

4. Standardisation of rates and

5. The case-control study

- The application of epidemiology to:

6. Screening and

7. Health care.

The first three choices are self contained topics and so fundamental that the reason for choosing them is self evident. Standardisation was picked as an example of the basic techniques for controlling for confounding, and because of the challenge to writers of explaining the similarities and differences between the direct and indirect method. The case-control study was a benchmark of how well methods were explained, with the issue of the odds ratio as an estimate of the relative risk providing fertile material to assess the explanation of an important theme in analysis and interpretation. Increasingly, epidemiology is being applied to health care and several books are on this alone. I chose screening as a long established theme in introductory epidemiological books, and health care as a relatively neglected but emergent theme. As with any other sample, bias can lead to an erroneous conclusion. This sampling, however, permits comparison between books and a review suitable as a journal article rather than a book in itself!

On average about three hours were spent per book. The material was found using the contents page, index, and by quickly scanning the pages. I have veered to description rather than critique, though I have given some opinion. The books are placed in some approximate order of complexity and are also summarised in table 1. Cost is not given, for in my view this is trivial in relation to the true cost (and value) of an epidemiological education. (Where books are similar, the cost may occasionally be influential.)

This is, of course, a personal and subjective review. Nonetheless, I hope there is enough factual material to help steer students and teachers, even when they do not agree with my opinions. 
Table 1 Summary of the 25 reviewed books

\begin{tabular}{|c|c|c|c|c|c|}
\hline Authors $\mathcal{E}$ ref no & $\begin{array}{l}\text { Year, ed, E् pages of } \\
\text { main text (size of } \\
\text { pp if small or large) }\end{array}$ & Scope $\mathcal{E}$ setting(s) & $\begin{array}{l}\text { Focus on theory } \mathcal{E} \\
\text { method, or } \\
\text { application, or both? }\end{array}$ & $\begin{array}{l}\text { Exercises and/or } \\
\text { study questions? }\end{array}$ & Audience? \\
\hline Ahlbom A, Norell S & $1^{\text {st }} 198476$ (small) & Epidemiology & Theory & Yes & U/grad \\
\hline Barker DJP, Rose $\mathrm{G}^{2}$ & $\begin{array}{l}4^{\text {th }} 1990152 \\
\text { (small) }\end{array}$ & Epidemiology, public health, clinical & Application, theory & No & U/grad \\
\hline $\begin{array}{l}\text { Beaglehole R, Bonita R, } \\
\text { Kjellstrom } \mathrm{T}^{6}\end{array}$ & $1^{\text {st }} 1993153$ & Epidemiology, public health & Theory, application & Yes & U/grad \\
\hline Coggon D, Rose G, Barker DJP' & $\begin{array}{l}3^{\text {rd }} 199363 \\
\text { (small) }\end{array}$ & Epidemiology & Theory & No & U/grad \\
\hline Farmer $\mathrm{R}$, Miller $\mathrm{D}$, Lawrenson $\mathrm{R}^{10}$ & $4^{\text {th }} 1996274$ & Epidemiology, public health & Theory, application & No & U/grad (parts, p/grad) \\
\hline $\begin{array}{l}\text { Fletcher RH, Fletcher SW, } \\
\text { Wagner EH } \mathrm{EH}^{24}\end{array}$ & $3^{\text {rd }} 1996270$ & Epidemiology, clinical & Theory, application & No & $\begin{array}{l}\text { P/grad, practitioner, } \\
\text { u/grad }\end{array}$ \\
\hline Friedman $\mathrm{GD}^{14}$ & $\begin{array}{l}4^{\text {th }} 1994328 \\
\text { (small) }\end{array}$ & Epidemiology, clinical, public health & Theory & Yes & P/grad, u/grad \\
\hline Friis RH, Sellers TA ${ }^{8}$ & $1^{\text {st }} 1996403$ & $\begin{array}{l}\text { Epidemiology, occupational, social } \\
\text { science }\end{array}$ & Theory, application & Yes & $\begin{array}{l}\text { U/grad, p/grad, } \\
\text { practitioner }\end{array}$ \\
\hline Gordis $\mathrm{L}^{13}$ & $1^{\text {st }} 1996263$ & Epidemiology, public health, clinical & Theory, application & Yes & $\begin{array}{l}\text { P/grad, practitioner, } \\
\text { U/grad }\end{array}$ \\
\hline $\begin{array}{l}\text { Greenberg RS, Daniels SR, } \\
\text { Flanders WD, Eley JW, } \\
\text { Boring JR }{ }^{9}\end{array}$ & $2^{\text {nd }} 1996178$ & Epidemiology, clinical & Theory, application & Yes & U/grad, p/grad \\
\hline Harkness $\mathrm{GA}^{12}$ & $1^{\text {st }} 1995262$ & Epidemiology, public health, nursing & Theory, application & Yes & $\begin{array}{l}\text { P/grad, practitioner, } \\
\text { u/grad }\end{array}$ \\
\hline Hennekens $\mathrm{CH}$, Buring $\mathrm{JE}^{17}$ & $1^{\text {st }} 1987344$ & Epidemiology & Theory, application & Yes & P/grad, researcher \\
\hline Jekel JF, Elmore JG, Katz $\mathrm{DL}^{7}$ & $1^{\text {st }} 1996272$ & $\begin{array}{l}\text { Epidemiology, statistics, clinical, } \\
\text { public health }\end{array}$ & Theory, application & No & U/grad, p/grad \\
\hline Lilienfeld D, Stolley $\mathrm{PD}^{16}$ & $3^{\text {rd }} 1994285$ & Epidemiology & Theory, application & Yes & P/grad, u/grad \\
\hline Mausner J, Kramer $\mathrm{S}^{15}$ & $2^{\text {nd }} 1985353$ & Epidemiology, occupational & Theory, application & No & $\begin{array}{l}\text { P/grad, u/grad, } \\
\text { researcher }\end{array}$ \\
\hline McMahon B, Trichopoulos $\mathrm{D}^{18}$ & $2^{\text {nd }} 1996302$ & Epidemiology & Theory & No & $\begin{array}{l}\text { P/grad, researcher, } \\
\text { practitioner }\end{array}$ \\
\hline $\begin{array}{l}\text { Morton RF, Hebel JR, } \\
\text { McCarter } \mathrm{RJ}^{20}\end{array}$ & $4^{\text {th }} 1996198$ & Epidemiology & Theory, application & Yes & U/grad, p/grad \\
\hline Norell $S^{21}$ & $1^{\text {st }} 1995190$ & Epidemiology & Theory & Yes & P/grad \\
\hline $\begin{array}{l}\text { Page RM, Cole GE, } \\
\text { Timmreck TC }\end{array}$ & $\begin{array}{l}1^{\text {st }} 1995392 \\
\text { (large) }\end{array}$ & Epidemiology, statistics & Theory, application & Yes & $\begin{array}{l}\text { U/grad, p/grad, } \\
\text { practitioner }\end{array}$ \\
\hline Rothman $\mathrm{KJ}^{19}$ & $1^{\text {st }} 1986349$ & Epidemiology & Theory & No & P/grad, researcher \\
\hline $\begin{array}{l}\text { Sackett DL, Haynes RB, } \\
\text { Guyatt GH, Tugwell } \mathrm{P}^{25}\end{array}$ & $2^{\text {nd }} 1991421$ & Epidemiology, clinical & Application, theory & No & $\begin{array}{l}\text { Practitioner,p/grad, } \\
\text { u/grad }\end{array}$ \\
\hline Schuman $\mathrm{SH}^{23}$ & $1^{\text {st }} 1986217$ & Epidemiology, clinical & Application, theory & No & Practitioner \\
\hline Silman $\mathrm{AJ}^{22}$ & $1^{\text {st }} 1995166$ & Epidemiology & Application & No & Practitioner, p/grad \\
\hline Timmreck TC ${ }^{11}$ & $1^{\text {st }} 1994415$ & Epidemiology & Theory, application & Yes & Unsure \\
\hline Unwin N, Carr S, Leeson $\mathrm{J}^{3}$ & $1^{\text {st }} 1997145$ & Epidemiology, public health & Theory, application & Yes & U/grad \\
\hline
\end{tabular}

U/grad, undergraduate; p/grad, postgraduate.

\section{Review}

Summary descriptive data are given in table 1 .

BASIC BOOKS, PROBABLY SUITABLE FOR UNDERGRADUATES AND PROFESSIONALS WITH LITTLE PREVIOUS EXPOSURE TO EPIDEMIOLOGY

Epidemiology for the uninitiated (Coggon D, Rose, $G$, and Barker $D \mathcal{F} P$ )

Epidemiology for the uninitiated ${ }^{1}$ is said to be for the novice. It is described as short (true) and authoritative. The opening places epidemiology in its population context and introduces comparison between groups as its key strategy. Chapters on disease measurement are sufficient, but the chapters on study design are skimpy. There are no references, a short bibliography is a mix of books for the novice and advanced texts; there are no exercises, no summaries (though each chapter is one). Information on concepts is minimal. This text could be read in two hours, and absorbed in a day.

- Population: three pages emphasise the concept.

- Causality: necessary, but insufficient!

- Natural history of disease: not covered, not indexed, but referred to in screening.

- Standardisation of rates: you can find out how to do it in three pages, but not why, which method to choose, or what the limitations are.

- Case-control study: the idea is introduced but nothing on analysis and interpretation.
- Screening: the background needed to understand why screening programme evaluation may be difficult is covered, but knowledge of sensitivity and specificity is assumed (not indexed).

- Health care epidemiology: not covered.

Overall verdict: a quickie for undergraduates, but too limited.

\section{Epidemiology in Medical Practice (Barker D f P, Rose G)}

Epidemiology in Medical Practice ${ }^{2}$ is said to be for clinicians and medical undergraduates. The approach is squarely public health, not clinical epidemiology. There are three sections: description of disease in the community, prevention of disease, and epidemiology and patient care. There is some repetition and fragmentation of material on study methods. There are no references, no exercises, no synthesis, and no history of the subject, but there is breadth and deep insight here.

- Population: brief differentiation of the epidemiological and demographic concepts.

- Causality: covers the basics and introduces the nuance of causes in populations versus the individual.

- Natural history: not defined or indexed, but is the dominant theme of a chapter on outcome and prognosis. 
- Standardisation of rates: a good worked example, but no explanation of why, which method to choose or the limitations.

- Case-control study: the material is integrated effectively with that on cohort studies, bias and causation and is very clear. Analysis and interpretation are not covered.

- Screening: the clinical and public health background and the assessment of screening tests are covered, but the difficulties of evaluation are not.

- Health care epidemiology: effective chapter focusing on need, demand, and evaluation, not planning or policy.

Overall verdict: much to commend it to medical undergraduates.

\section{An Introductory Study Guide to Public Health and Epidemiology (Unwin N, Carr S, Leeson F)}

An Introductory Study Guide to Public Health and Epidemiology ${ }^{3}$ hopes to introduce nursing students and practitioners to the "public health perspective". It engages the student in critical thinking with each chapter starting with questions and study outcomes, and integrating numerous exercises in the text giving them high priority (the student is encouraged to do them before reading on). There is a "summary" which is a set of questions with space so it can be written by the student; a novel idea! A policy of avoiding calculations, deliberate or otherwise, seems to be in effect; sometimes to the detriment of the book.

- Population: the population idea, and the prevention paradox, is introduced giving a flavour of the epidemiological concept of population.

- Causality: there is a clear-cut framework and a broad consideration of the concept in epidemiology, but the discussion of judging the likelihood of causality is bare.

- Natural history: not found.

- Standardisation of rates: exemplary text, examples, and interpretation which would have been strengthened by asking students to do the calculations.

- Case-control study: the essence of the design is captured in three easy pages and a diagram.

- Screening: a detailed exposition of screening, but not strong on evaluation or explaining difficult ideas like lead time bias. It avoids calculation of the measures of the quality of a test, but can students understand the concepts of sensitivity and specificity without an example or calculation?

- Health care epidemiology: there is heavy emphasis on applications with four chapters (health promotion, health needs assessment, and two on effectiveness of health care), but only occasionally do they draw upon or integrate with the epidemiology.

Overall verdict: this book fills a niche. It integrates passive and active learning, and is consistently introductory. I doubt if nurses would recognise that this book was written for them. It is an option for anyone starting out in epidemiology and will appeal to those who like ideas and are wary of numbers.
Introduction to Modern Epidemiology (Ahlbom $A$, Norell $S$ )

Introduction to Modern Epidemiology ${ }^{4}$ is inspired by the approach taken by the Harvard approach captured by Rothman's Modern Epidemiology (see below) and uses the same definition, the science of the occurrence of disease in human populations. This book echoes many ideas in Rothman's text. Its characteristics are brevity and exercises. The exercises and answers occupy about 35 of the 97 pages. The exercises clearly convey the message that this vision of epidemiology is about quantifying disease and designing studies. The difficulty of many of the exercises contrasts with the brevity of the explanatory text.

- Population: is not specifically discussed.

- Causality: the definition used is simple: reducing the causal factor reduces the disease, with no discussion of the immense difficulties in practice, and the discussion is focused on one model (necessary and sufficient).

- Natural history of disease: not covered.

- Standardisation of rates: in two pages you can learn about the conceptual basis of both direct and indirect standardisation, but not which method to choose or the limitations. The associated exercises are testing.

- Case-control study: the short discussion is unbalanced. For example, the reasons for doing case-control studies are handled in a sentence or two, but the mode of analysis to generate a "relative risk" and the advantages over cohort studies occupy more than two pages.

- Screening: the idea of screening and screening programme evaluation are not covered, but the chapter on sensitivity and specificity is very clear. Unusually, the effect of sensitivity and specificity on errors in measuring prevalence is emphasised.

- Health care epidemiology: not covered.

Overall verdict: The preface says that newer concepts have been woven into the existing dogma. As with Modern Epidemiology, one aim seems to be to contest if not elbow out the "established dogma". Books which offer a different view are of especial value for postgraduates and this may be good preparation for tackling the tougher Modern Epidemiology.

\section{Basic Epidemiological Methods and Biostatistics} (Page R M, Cole G E, Timmreck T C)

Basic Epidemiological Methods and Biostatistics is designed for diverse courses. It emphasises learning concepts and principles through application. Chapters include objectives, summaries, key terms, tough exercises (answers given) and references. Review questions and detailed examples of studies sprinkle the book. The first chapter, introducing the principles and history of epidemiology, is followed by eight on methods. There is emphasis on infectious disease epidemiology. The book closes with questions for self-evaluation. A glossary and an excellent book list are included.

- Population: no solid discussion.

- Causality: clear foundation material. 
- Natural history: short, but rounded explanation.

- Standardisation of rates: exceptional clarity with involvement of the reader in performing the calculations.

- Case-control study: a straightforward explanation except for confusing text on the basis of the odds ratio as an estimate of the relative risk. The case-control study is also detailed in a chapter on thinking through doing a study to solve a problem.

- Screening: not discussed, but sensitivity and specificity considered in relation to validity.

- Health care epidemiology: not considered.

Overall verdict: Good for methods and some concepts and of especial value for readers who like self-study. Despite its size this book is about right for the undergraduate.

\section{Basic Epidemiology (Beaglehole R, Bonita R, Kjellstrom T)}

Basic Epidemiology, ${ }^{6}$ a succinct WHO product, is said to be for an international audience of undergraduate medical and public health students and for health professionals. There is a separate teacher's guide. In 167 illustrated pages it covers epidemiology and its applications, and throws in chapters on statistics and continuing epidemiological education. The opening emphasises the uses of epidemiology and its achievements. The remainder gives the ideas behind, limitations of, and interpretation of epidemiological studies. For example, the case-control study is described in two pages while causation in epidemiology has 11 . Communicable disease epidemiology, clinical epidemiology, environmental and occupational epidemiology and health service and policy all receive a chapter. A comprehensive reference list and a set of study questions and answers round off this remarkable book.

- Population: concise paragraph.

- Causality: first rate discussion of the key ideas, in 11 pages.

- Natural history: very short coverage.

- Standardisation of rates: the idea is explained, but not how to do it or the pros and cons of different methods.

- Case-control study: clear exposition of the idea with examples all in about three pages.

- Screening: everything the undergraduate needs to know in about four pages.

- Health care epidemiology: comprehensive, compact discussion of epidemiology in both planning and policy.

Overall verdict: this book presents a broad and deep vision of the role of epidemiology and is admirably suited to undergraduates, but would repay study by everyone.

\section{Epidemiology, Biostatistics and Preventive} Medicine (Fekel f F, Elmore f G, Katz DL)

Epidemiology, Biostatistics and Preventive Medicine $e^{7}$ justifies its ambitious goal of providing comprehensive and integrated content as logical because epidemiology is the science of preventive medicine and public health and biostatistics is the quantitative foundation of epidemiology. It accomplishes this goal! The target audience is medical students and professionals. The text is in two tones, clearly laid out, and referenced. There are no exercises or study questions.

- Population: mentioned in passing.

- Causality: fully and mostly logically discussed with good examples, but uses inadequately defined concepts and terms.

- Natural history: patchy discussions at odds with my understanding.

- Standardisation of rates: crystal clear in less than three pages, but stops short of discussing pros and cons of each method.

- Case-control study: the two to three page discussion is adequate, but the material is fragmented.

- Screening: postgraduates should read the rich discussion of screening tests and programmes, which covers all the usual material and Bayes' theorem.

- Health care epidemiology: health care and public health are amply discussed, but not in the context of epidemiology.

Overall verdict: impressive package, though the variable depth of coverage is confusing: some parts are elementary, some complex.

\section{Epidemiology for Public Health Practice (Friis $R$ $H$, Sellers $T A$ )}

Epidemiology for Public Health Practice ${ }^{8}$ is intended for a broad audience, but social science students specifically. An emphasis on practical public health problems is its basis, and the book opens with "A nightmare in Nigeria" a potentially serious environmental threat that caused consternation for residents and the New York state Health Department. Chapters are organised around learning objectives, outlines, case studies, study questions and exercises, and plentiful references. Infection, occupational health and, uniquely, psychology, behaviour, and social factors are picked out for specific chapters.

- Population: not explained.

- Causality: interesting, up-to-date, historically based account.

- Natural history: a discussion was not found, but the term is used.

- Standardisation of rates: brief material which requires careful reading.

- Case-control study: a highly readable and clear 12 page account. The odds ratio is particularly well explained.

- Screening: the material is admirably chosen and comprehensive excepting evaluation of screening programmes which is too brief

- Health care epidemiology: in about four pages the scope of epidemiology in health care is introduced.

Overall verdict: There is much of value here. The scenarios are lively. The depth is variable.

Medical Epidemiology (Greenberg $R S$, Daniels $S$ $R$, Flanders $W D$, Eley $\mathcal{F} W$, Boring $\mathcal{f} R$ )

Medical Epidemiology ${ }^{9}$ is written for medical students. The authors hope that it will suit others, but it demands a medical vocabulary (the glossary covers only epidemiology). In addition to the basics, there are chapters on 
epidemiology in genetics, clinical decision making, and interpreting the epidemiological literature. Each chapter starts with a patient profile, and has chapter summaries, rich and interesting illustrations, study questions using the MCQ format, and ample further reading and references.

- Population: there is some discussion of the population concept, but the message is confused by the unrelenting emphas on individuals, eg epidemiologists are said to examine disease in groups to learn why certain individuals (my emphasis) develop the disease and others do not. But, epidemiology informs us why certain groups of individuals get disease.

- Causality: a realistic scenario of breast cancer risk in a woman whose mother died of the disease leads into a clear discussion which stresses the difficulties in reaching a decision.

- Natural history: the weakness of the index is shown by the lack of an entry for a subject which is given attention, but with emphasis on the course of disease around and after diagnosis.

- Standardisation of rates: not indexed, but there is a good example of direct standardisation and clear text.

- Case-control study: the discussion is deep and detailed, particularly on the benefits and disadvantages of matching. Some weaknesses in the book are apparent here. First, the case material on eosinophilia myalgia syndrome gets in the way of the exposition. Second, there are errors eg misspelling, and use of Reye's syndrome in fig 9.2 instead of eosinophilia myalgia syndrome, as stated in the text and legend.

- Screening: detailed discussion of screening tests and programme evaluation in the context of breast cancer.

- Health care epidemiology: not covered.

Overall verdict: a challenge for undergraduate medical students for whom it is custom designed. It may well capture their attention, but will it orientate them to the population based, public health responsibilities of the medical profession or will they see epidemiology as a tool for individually orientated clinical practice?

Lecture notes on Epidemiology and Public Health Medicine (Farmer $R$, Miller D, Lawrenson R)

Lecture notes on Epidemiology and Public Health Medicine $^{10}$ is aimed at medical students and doctors, and argues that medicine and epidemiology are intertwined. The material is organised into three sections: epidemiology ( $45 \%$ of the book), prevention and control of diseases $(30 \%)$, and health services (15\%). Cause and risk provide the lead into the epidemiological methods. The role of epidemiology is clear in relation to prevention, but there is no integration of health care and epidemiology. The use of a chapter index, ample headings, and brief examples of published studies ensures clarity of organisation. Green tones to highlight headings, boxes, tables, and figures gives unusual freshness. There are no exercises or text references (though further readings are relevant).

- Population: insubstantial regarding epidemiology, but ample on demography.

- Causality: covers the basics, but defines causes and determinants as different which is curious.

- Natural history: passing statements, but no proper discussion.

- Standardisation of rates: skeletal text with worked examples.

- Case-control study: complex language is a barrier, but the text is clear and logical, and four brief and important examples illustrate the power and limitations of the method.

- Screening: 12 exquisitely clear pages cover everything but the difficulties of evaluation.

- Health care epidemiology: the material on health care does not get to grips with how epidemiology fits in.

Overall verdict: suitable for the medical undergraduate, and a gentle introduction to those training in public health medicine. The publisher's claims that it sets epidemiology into a global and clinical context and helps doctors to make clinical decisions are exaggerations.

An Introduction to Epidemiology (Timreck $T C$ )

An Introduction to Epidemiology ${ }^{11}$ claims to be a basic text for a range of health degree programmes at undergraduate and postgraduate levels and a handbook for field epidemiologists. Each chapter has explicit objectives, much detail, coverage of practice and principles and stretching study questions to which answers are in a separate instructors' manual. The history of epidemiology is detailed, while the material on statistics is limited to description of disease patterns. The appendix contains five major case studies.

- Population: not specifically discussed.

- Causality: a repetitive, long, infectiondominated, and awkward discussion which makes a difficult topic...difficult.

- Natural history of disease: not found and not indexed.

- Standardisation of rates: inadequate yet repetitive explanation of the underlying concept and no instruction or examples of how to do it.

- Case-control study: confusing terminology characterises an idiosyncratic account.

- Screening: the lengthy text does not cover screening programme evaluation.

- Health care epidemiology: not covered.

Overall verdict: an idiosyncratic amalgam of material, with a heavy infection focus. Not clear enough for undergraduates and insufficient depth for postgraduates.

MORE ADVANCED BOOKS, PROBABLY FOR POSTGRADUATES AND PROFESSIONALS WITH SOME PREVIOUS BACKGROUND IN EPIDEMIOLOGY

Epidemiology in Nursing Practice (Harkness $G$ A) Epidemiology in Nursing Practice ${ }^{12}$ examines the principles from a nursing perspective, shows the uses of epidemiological knowledge and methods in both practice and the evaluation of 
practice. The book has two major sections: concepts and applications. The latter is written by authors in practice, the former mainly by Harkness. Part 1 is opened by a diagram juxtaposing Florence Nightingale's lamp and the Broad Street Pump. The book has an appendix on presenting data and a glossary. Each chapter has objectives, key words, a summary, critical thinking questions, references, and is richly and imaginatively illustrated. The book borrows examples freely from other texts. I was struck by the huge, but largely ignored, contribution of Florence Nightingale (and other nurses) to epidemiology and public health. Nightingale's bold, imaginative and effective polar area diagrams ( $p 10)$ should be seen by all epidemiologists.

- Population: the idea suffuses the text, but is not specifically discussed.

- Causality: in three pages the complexity of the subject is captured together with the basics of the epidemiological approach.

- Natural history: set and discussed in the context of prevention but not as a key concept in its own right.

- Standardisation of rates: the direct method is explained adequately, but the indirect method is covered poorly and the example is not illuminating.

- Case-control study: extremely helpful exposition with a first class example.

- Screening: a solid introduction to the practice of screening precedes the epidemiological principles, which are effectively stated.

- Health care epidemiology: several chapters discuss and demonstrate how epidemiology is put to use in policy and practice.

Overall verdict: A comprehensive introduction to the science and craft of epidemiology which more than achieves its objectives. Potentially of great interest to health professionals, nurses and non-nurses alike.

\section{Epidemiology (Gordis L)}

Epidemiology $y^{13}$ has the goal of demonstrating that epidemiology is essential to clinical practice and health care and not just public health and health policy. A mixture of theory, application, inspiring examples, a rich selection of illustrations and, uniquely, humorous cartoons, is effectively integrated. The structure is logical and coherent. Basic concepts are briefly and clearly reviewed. Sources of data and measurement of disease are presented within a critical framework. The terminology and content is modern but many examples (often borrowed from other textbooks) are historical. Summaries and multiple choice review questions end each chapter. The book is modernfor example, genetic markers are given prominence in the discussion of environment/genetic interactions. The practical applications of epidemiology are made explicit in four chapters. The book's hallmark is integration, a diffcult task eased by single authorship.

- Population: no specific discussion.
- Causality: a dominating theme strongly illustrated in the context of modern day problems.

- Natural history of disease: thorough, and focused on clinical prognosis and screening.

- Standardisation of rates: short text with very effective examples.

- Case-control study: 15 pages of clear explanation with a first class exposition on the odds ratio.

- Screening: full coverage, albeit in separate sections, of the evaluation of both screening tests and of programmes.

- Health care epidemiology: evaluation is covered and to a limited extent development of health policy. Health needs assessment and priority setting are not.

Overall verdict: Great merit as an introduction for postgraduates, and excellent potential for use selectively with undergraduates.

\section{Primer of Epidemiology (Friedman GD)}

Primer of Epidemiology ${ }^{14}$ is aimed at physicians, medical students, and other health care professionals. The clinical emphasis is strong with a chapter on epidemiology in clinical practice. The writing is clear and brief yet the explanations avoid oversimplification. Multivariate analysis is introduced clearly. Chapters contain open and closed questions with detailed answers. The last chapter summarises each chapter! There is emphasis on doing epidemiology, with detailed discussion throughout of published studies and a chapter on how to do a study. Weight is given to the cross-sectional study. This text is a general book which embraces clinical epidemiology.

- Population: no specific discussion.

- Causality: a straightforward account, weakened by absence of solid examples.

- Natural history of disease: insufficient even for the undergraduate.

- Standardisation of rates: short and inadequate on the indirect method.

- Case-control study: the 25 page chapter is clear but sits uneasily between the needs of postgraduates and undergraduates. Three summaries of actual studies are interesting, informative and well chosen, adding great value to the theoretical material.

- Screening: succinct, and interesting.

- Health care epidemiology: minimal coverage.

Overall verdict: Good for examples, exercises, and selected readings.

\section{Epidemiology-an Introductory Text (Mausner $\mathcal{F}$ $S$, Kramer S)}

Epidemiology-an Introductory Text ${ }^{15}$ is for a broad range of students for the authors contend that all health professionals should be familiar with epidemiology. In addition to the usual principles and methods, this book has chapters on population and health and occupational epidemiology. The first two chapters emphasise that epidemiology underpins population medicine, and particularly prevention. Measurement is given prominence. A concise illuminative discussion of time, place, and 
person is developed as descriptive epidemiology, while all formal studies are under the umbrella term "analytic" and subdivided into observational and experimental. Observational studies are again divided into retrospective and prospective, the terms case-control and cohort being subservient. The cross-sectional design is dismissed in a paragraph while the trial gets a full chapter. Causality is only discussed in the context of analytic studies. The rationale for a chapter on demography is unclear, as is the reasoning for two specific aspects of epidemiology, infection and occupation. Both chapters introduce new concepts.

- Population: emphasis on population as related to epidemiology and demography.

- Causality: a rounded discussion with good examples.

- Natural history of disease: a clear account sufficient for undergraduates (not indexed).

- Standardisation of rates: a clear exposition with good examples but dispersed across chapters.

- Case-control study: unfortunately these are called retrospectives studies in chapter 7 and case-control in chapter 12 (and the index refers only to the latter). In about 15 pages the student is given a foundation for advanced study.

- Screening: a 24 page chapter covers the subject comprehensively and clearly.

- Health care epidemiology: not covered.

Overall verdict: The book has breadth, crystal clear explanations of concepts, and pertinent examples. It was published in 1985, and uses nomenclature and classification which have now been superseded. I have used this book for 10 years to great advantage and hope a much needed revision is forthcoming.

\section{Foundations of Epidemiology (Lilienfeld D E, Stolley $P$ D)}

Foundations of Epidemiology ${ }^{16}$ hopes to integrate the concepts and applications of epidemiology for both students and practitioners. The emphasis is on aetiology. Notable strengths are both American and European perspectives, chapter summaries, exercises and answers, an appendix of statistical methods, a concise history of epidemiology, and both author and general index. Discussion of time, place, and person is fragmented across chapters. Some terms are confusing. For example the concept of "demographic" studies in epidemiology (studies of mortality and morbidity statistics) is unfortunate, particularly as these are said to be studies of populations, as distinct from epidemiological studies which are said to be of individuals. The terms concurrent and nonconcurrent are used as qualifiers for cohort studies. The idiosyncrasies also apply to concepts as in the definition of ecological fallacy, which is defined as a confounding variable, and the natural history of disease and the spectrum of human response are conflated. A chapter on epidemiology in clinical practice consists of leftovers.

- Population: no distinct discussion, but the concept infuses the text.
- Causality: a historically based 13 page clear account.

- Natural history of disease: discussed briefly as the spectrum of disease.

- Standardisation of rates: four pages of crystal clear text with an effective example.

- Case-control study: 22 pages of clear explanation with excellent examples and extra statistical material in appendices ensures suitability for the postgraduate.

- Screening: skeletal coverage in the context of a chapter on morbidity statistics.

- Health care epidemiology: not covered.

Overall verdict: A postgraduate text which has many strengths (which have gained it a big reputation), but is not comprehensive and has idiosyncrasies in the terminology (it needs revision, and opportunities to do this in recent editions have not been taken).

\section{Epidemiology in Medicine (Hennekens $C H$, Buring $\mathcal{F}$ E)}

Epidemiology in Medicine ${ }^{17}$ aims to be a bridge to advanced work. The emphasis, however, is on methods, including statistics, and despite the title it is not focused on clinical epidemiology. Chapters are fully referenced and end in study questions. Screening is the sole topic of the section on disease control. This is a methods book which skips many of the concepts key to the practice of epidemiology, whether in public health or medicine.

- Population: alluded to in the opening pages.

- Causality: cause and effect is thoroughly discussed in the context of interpretation of associations with a detailed example of smoking.

- Natural history: not indexed and covered in passing under screening.

- Standardisation of rates: both the direct and indirect methods are clearly explained but the two are not contrasted.

- Case-control study: the material is detailed and clear but fragmented across chapters.

- Screening: a full and straight account.

- Health care epidemiology: not covered.

Overall verdict: this book glosses over some fundamentals concepts but is a readable advanced book for the postgraduate already equipped with some of the concepts. (The book is greatly appreciated by students.)

\section{Epidemiology: Principles and Methods} (McMahon B, Trichopoulos D)

Epidemiology: Principles and Methods ${ }^{18}$ is said to be for the novice and a bridge to more advanced material. Its systematic examination of variation in disease as the underlying strategy of epidemiology and the chapters on cause, and time, place, and person are the backbone of the book. The list of 613 references is a huge resource. There is an emphasis on causal epidemiology, with nearly half of the book devoted to cohort and case-control studies, and virtually nothing on cross sectional and trial designs. Some concepts are well discussed but others (iceberg of disease and epidemiological triangle) are omitted. 
- Population: no substantial discussion.

- Causality: a critical, original and full discussion.

- Natural history of disease: brief and insufficient for undergraduates.

- Standardisation of rates: an exposition made difficult without examples or illustrative data.

- Case-control study: 73 pages of advanced material for researchers planning such a study.

- Epidemiology of screening: not covered

- Health care epidemiology: not covered.

Overall verdict: a resource for selective reading, not an introductory textbook.

\section{Modern Epidemiology (Rothman K $\mathcal{F}$ )}

Modern Epidemiology ${ }^{19}$ has two ambitious goals, to integrate the ideas of epidemiology as a science and to present the material simply so it is useful to novice and advanced student alike. The passionate argument that epidemiology is a coherent and distinct science (albeit "an embryo") with its own theory is introduced early, particularly by placing it in the context of the history of science and of causal thinking. Measurement and analysis of the occurrence of disease is the focus of the book, which introduces types of epidemiological study in 26 pages compared to about 160 for analysis. The text is passionately written, with the overt wish to overturn traditional tenets. The chapters end with a summary and references but there are no self-tests of understanding.

- Population: not explained.

- Causality: complex discussion of a general model of causation is followed by a nihilistic treatment of the epidemiological criteria for causality, as proposed by Hill and many others.

- Natural history: not covered.

- Standardisation of rates: in 9 pages, with a striking example, the underlying unity of conception of the direct and indirect methods, and the theoretical fault in comparing two SMR's with each other, is demonstrated.

- Case-control study: advanced and critical evaluation of the study in the context of the paradigms of science.

- Screening: not covered.

- Health care epidemiology: not covered.

Overall verdict: a thought provoking book to challenge the advanced postgraduate, and the researcher, who wants to rethink epidemiology. Modern epidemiology, however, is broadening its theory and applications while this book would have us think of the science as somewhat narrow, and focused on measurement.

BOOKS WHICH EMPHASISE SELF LEARNING, EXERCISES AND THE PRACTICAL APPLICATION OF EPIDEMIOLOGY

A study guide to epidemiology and biostatistics (Morton R F, Hebel F R, McCarter R F)

$A$ study guide to epidemiology and biostatistics ${ }^{20}$ is designed for a wide range of health science students and for either self instruction or as a companion to a didactic course. It comprises notes on the principles, a large set of exercises (which are the crux of the book), and multiple choice questions. Two overall goals- to use epidemiological methods to evaluate evidence for medical decision making and assess data using epidemiological and statistical principles-and 45 objectives are given together with expected performance on the MCQ. The objectives are as specific as "define incidence and prevalence", and as general as undertake "critical examination of a published scientific article". Each chapter has objectives, explanatory text, exercises, answers, and guided reading. The book ends with 13 blank pages, so there is no excuse for evading the exercises!

- Population: emphasised in the definition, but not indexed.

- Causality: the discussion focuses on interpretation of associations, in the light of causal criteria. The associated questions are elementary in the extreme and do not test whether the ambitious objectives have been achieved.

- Natural history of disease: not indexed or discussed but knowledge is assumed in discussing screening.

- Standardisation of rates: not indexed, but direct standardisation is covered excellently. The questions reach but do not advance the reader's knowledge beyond the explanatory text.

- Case-control study: a thoughtful, readable, well illustrated exposition. The associated exercises are searching.

- Screening: the ideas behind screening are covered but programme evaluation is not. The material on sensitivity and specificity is very clear and the exercises develop understanding.

- Health care epidemiology: not covered.

Overall verdict: All students and teachers should be aware of this book which would be ideal for students who learn by doing. The coverage of principles may just suffice for undergraduates, but postgraduates will need much more.

\section{Workbook of Epidemiology (Norrell S E)}

Workbook of Epidemiology ${ }^{21}$ proposes to fill the gap between the principles and applications of epidemiology. It does this by the use of hundreds of exercises and questions, supported by sparse text. Altogether 116 pages of answers are added to the 190 on general text.

- Population: not covered.

- Natural history: not done.

- Causality: some notes but not systematic.

- Standardisation of rates: not covered.

- Case-control study: a few notes.

- Screening: only sensitivity and specificity are covered.

- Health care epidemiology: not covered. Overall verdict: a specialist book for those equipped with the basics, or willing to work with a general textbook, and wish to learn the techniques of a few study designs through self test and examples. 
Epidemiological Studies: A Practical Guide (Silman A)

Epidemiological Studies: $A$ Practical Guide ${ }^{22}$ has the tough but limited roles of filling the gaps between the theoretical texts and texts on disease epidemiology and training readers to undertake simple epidemiological studies themselves. It does so in a systematic and clear manner (a cookbook style). There are no exercises for the reader to test out their understanding and no references. There are ample unreferenced, and presumably fictional, examples.

- Population: no discussion of concept but patient populations are seen as distinct from well ones.

- Causality: Touched on but the reader would need to go elsewhere for understanding.

- Natural history: no discussion.

- Standardisation of rates: the reader is unlikely to understand or be able to apply the technique after reading the $3 / 4$ page text.

- Case-control study: the tools to do and analyse this type of study are provided, albeit across several chapters.

- Screening: the relationship between sensitivity and specificity is covered in the context of validity, not screening.

- Health care epidemiology: not covered.

Overall verdict: less than the title implies, but eminently suitable for those primed with theory and ready to do cross sectional, case-control, and cohort surveys.

BOOKS INTRODUCING EPIDEMIOLOGY IN CLINICAL PRACTICE

Practice-based Epidemiology: An Introduction (Schuman S H)

Practice-based Epidemiology: An Introduction ${ }^{23}$ is for clinicians but it is not clinical epidemiology but epidemiology to inspire them. Vivid case studies, a strong emphasis on clinical medicine and worked examples to show how straightforward the approaches can be, characterise the book. Each chapter has highlights, not summaries! There are no exercises, but ample references and examples.

- Population: not considered specifically.

- Causality: not specifically covered.

- Natural history: used not explained.

- Standardisation of rates: the idea is introduced but not the vital concepts of direct and indirect adjustment.

- Case-control study: not covered, except to define it.

- Screening: set in the context of clinical decision making, but principles are there.

- Health care epidemiology: not covered.

Overall verdict: Not for the student, but could serve to entice clinicians to the cause of epidemiology!

Clinical Epidemiology. The Essentials (Fletcher $R$ $H$, Fletcher $S W$, Wagner $E H$ )

Clinical Epidemiology. The Essentials ${ }^{24}$ is for clinicians (and medical students). Epidemiological and public health ideas and theory are interwoven into the clinical paradigm which the book follows. There are no exercises or detailed examples, but ample references and further reading.

- Population: a succinct discussion of the concept of population, the difference between the population at large and the population of patients, and the implications of studying the latter.

- Causality: a masterly account, meeting the needs of the senior student. (A minor gripe is that I found fig 11.10 an unconvincing and unhelpful simplification).

- Natural history: extremely brief!

- Standardisation of rates: cursory.

- Case-control study: a thorough and critical overview, set in the context of case studies and compared with the cohort study.

- Screening: a great strength of this detailed material is the rich clinical content.

- Health care epidemiology: not specifically covered.

Overall verdict: This book is fine epidemiology in any setting and has strengths for all postgraduates, not just those in medicine (indeed the examples may be particularly important to non-medical epidemiologists) and the keen undergraduate. But it is not comprehensive.

\section{Clinical Epidemiology. A Basic Science for} Clinical Medicine (Sackett D L, Haynes $R B$, Guyatt $G$ H, Tugwell P)

Oddly, the authors don't state the intended readership. Clinical Epidemiology $y^{25}$ is, however, for the user and not the doer of research. As medical and epidemiology students tend to "discover" this book it is wise for epidemiology teachers to know about it. It is more than clinical epidemiology, it is a primer on critical thinking and continuing education, and one of the three sections is on keeping up to date, the others being diagnosis and management. The chapters actively engage the reader by asking questions and by use of humour and anecdote. The authors don't disguise their personalities. Exercises are integrated into the text. There are ample references.

- Population: not covered.

- Causality: a discussion of the issues is set in the context of ascertaining whether a treatment causes a benefit or a side-effect and guidance on how to assess papers purporting to demonstrate cause and effect.

- Natural history: brief but highly relevant text.

- Standardisation of rates: not covered.

- Case-control study: the material is enough to warn the reader to interpret this research with care.

- Screening: the coverage is detailed and interesting, and set in the context of diagnostic tests and of early diagnosis.

- Health care epidemiology: not covered.

Overall verdict: Truly, the application of epidemiology to clinical medicine. An inspiration to the rigorous medical student and clinician and a huge resource to the general epidemiologist, wanting to see the science and craft from a new perspective. 
Conclusions and recommendations

There is remarkable diversity of approach, subject matter, content, and interpretation of basic facts and concepts. This is both encouraging and worrisome. The science and craft of epidemiology is diverse and textbooks should acknowledge this. Variety also helps to meet the needs of individuals. For example, some students benefit from objectives and summaries, others find them irksome. Some will do exercises and learn from them, others are looking for theoretical understanding. Nonetheless, there is a worrying diversity of terminology and interpretation of basic ideas such as whether the case-control study is a valuable or weak form of investigation. After this review, I am confused!

The conclusion is that both students and teachers need to be wary that the chosen book(s) are providing messages which, at least, are not at conflict with their own teachings and, at worst, are not simply misleading. The terminology is likely to be different in every book. This review has shown me just how important the Dictionary of Epidemiology by Last is. ${ }^{26}$ All students and courses will be reliant on that to translate across texts and courses. (In passing, epidemiology is no different to other disciplines; even mathematics, the paragon of precision, has numerous words for simple concepts such as multiplication eg product!)

Strikingly, some basic texts make little room for concepts. I was stunned by how the epidemiological idea of population health was so rarely discussed beyond the definition. The attention given to exercises and learning by doing (an important part of this group of textbooks) is welcome. Educationally beneficial exercises are, however, easier to create for calculations, but less easy for ideas such as causality, a problem which needs a solution if epidemiology is not to degenerate into medical arithmetic.

Most texts are north American but an increasing number are European (Beaglehole is an international collaboration). A distinction can be seen. European texts almost invariably embed their material in a public health or, less commonly, a clinical framework and emphasise practical applications. They are strong in making explicit the public health importance of epidemiology. North American texts are less tied to public health, more inclined to clinical examples, and are more technical with strong emphasis on methods and analysis.

Since the practical applications are dependent on the context, the value of texts which emphasise the applications are more limited internationally. For example, American texts put relatively little emphasis on gaining community based controls, and when they do, they emphasise random digit dialling to gain telephone controls-British ones emphasise the use of community registers. Nevertheless, there is much to be learned from transatlantic exchange of epidemiological ideas.

I was struck by how much there is for the generalist to learn from the specialist perspectives; for example the clinical epidemiology books teach a great deal of general epidemiology. The overall messages seem to me to be:

- Students are spoilt for choice and should exercise this privilege by examining options carefully for texts which suit their own learning style.

- Teachers should ensure their own emphases, terminology, and conceptual understanding is compatible with the text.

- There is a need for a more coherent vocabulary in epidemiology. Rothman explained this variability as a feature of an embryonic science, but growing up places responsibility on us all to define the language, to agree synonyms, and to vary only when the rationale is explicit and strong.

- To maximise the rewards of reading, students and teachers should use different texts for different topics, even though they may benefit from using one textbook for general reference.

Each epidemiologist will have their own favourites. I have always found Mausner and Kramer's explanations of concepts exemplary and brief; try it if you have a conceptual block (but sadly the book is outdated now). Rothman provides a serious challenge in methods and analysis. Sackett is simply something different, exciting, and important, at least in clinical care and its interface with public health. Jekel packs in a great deal for the beginner. Barker combines breadth and depth with surprising brevity. Morton is an attractive self reader and self test. The book by Gordis has become my overall favourite as a first serious textbook in epidemiology; it is ideal for the master's level entrant and has a great deal of material suitable for the undergraduate. It is modern in the sense that it encapsulates what epidemiology is trying to do in the 1990s and is up to date in terms of information.

I am grateful for the choice. I look forward to more.

Potential conflict of interest: Dr Nigel Unwin, first author of $A n$ Introductory Study Guide to Public Health and Epidemiology, has an appointment of Senior Lecturer in the Department of Epidemiology and Public Health, in which the author also works.

I thank: Professor Johann Mackenbach for suggesting this review; the editor and the editorial board of the Journal of Epidemiology and Community Health for inviting me to do it; Lorna Tittle of the JECH for helping acquire some of the books; Lorna Tittle of the JECH for helping acquire some of the books; all the colleagues and students who commented on earlier drafts but especially Denise Howel, Carl Shy, Richard Thomson,
Richard Edwards, David Chappel, and Halina Greiser. I also thank the University of Newcastle upon Tyne, and my colleagues in the Department of Epidemiology and Public Health, for supporting my sabbatical leave, which made the review possible. Finally, I thank the Department of Epidemiology at the School of Public Health, University of North Carolina at Chapel Hill for administrative (in particular by Betsy Seagroves) and academic support. The review was prepared while I held the post of Visiting Professor there.

1 Coggon D, Rose G, Barker DJP. Epidemiology for the uninitiated. London: BMJ Publishing Group, 1993.

2 Barker DJP, Rose G. Epidemiology in medical practice. London: Churchill Livingstone, 1990

3 Unwin N, Carr S, Leeson J. An introductory study guide to public health and epidemiology. Buckingham: Open University Press, 1997.

4 Ahlbom A, Norell S. Introduction to modern epidemiology. Chestnut Hill: Epidemiology Resources Inc, 1984.

5 Page RM, Cole, GE, Timmreck TC. Basic epidemiological methods and biostatistics. Boston: Jones and Bartlett Publishers, 1995.

6 Beaglehole R, Bonita R, Kjellstrom T. Basic epidemiology. Geneva: World Health Organisation, 1994. 
7 Jekel JF, Elmore JG, Katz DL. Epidemiology, biostatistics and preventive medicine. Philadelphia: WB Saunders Company,

8 Friis RH, Sellers TA. Epidemiology for public health practice. Gaithersburg: Aspen Inc, 1996.

9 Greenberg RS, Daniels SR, Flanders WD, Eley JW, Boring JR. Medical Epidemiology. Norwalk, Appleton and Lange, 1996.

10 Farmer R, Mille D, Lawrenson R. Lecture notes on epidemiology and public health medicine. Oxford: Blackwell Science Ltd, 1996.

11 Timmreck TC. An introduction to epidemiology. Boston: Jones and Bartlett Publishers, 1994

12 Harkness GA. Epidemiology in nursing practice. St Louis: Mosby-Year Book, Inc, 1995.

13 Gordis L. Epidemiology. Philadelphia: WB Saunders Co, 1996.

14 Friedman GD. Primer of epidemiology. New York: McGrawHill Inc, 1994.

15 Mausner JS, Kramer S. Epidemiology. Philadelphia: WB Saunders Co, 1985.

16 Lilienfeld DE, Stolley PD. Foundations of epidemiology. New York: Oxford University Press, 1994.
17 Hennekens $\mathrm{CH}$, Buring JE. Epidemiology in medicine. Boston: Little, Brown and Co, 1987.

18 McMahon B, Trichopoulos D. Epidemiology. Boston: Little Brown and Co, 1996.

19 Rothman KL. Modern epidemiology. Boston: Little, Brown and $\mathrm{Co}, 1986$.

20 Morton RF, Hebel JR, McCarter RJ. A study guide to epidemiology and biostatistics. Gaithersburg: Aspen Publishers Inc, 1996

21 Norell SE. Workbook of epidemiology. New York: Oxford University Press, 1995.

22 Silman AJ. Epidemiological studies: a practical guide. Cambridge: Cambridge University Press, 1995.

23 Schuman SH. Practice-based epidemiology. New York: Gordon and Breach Science Publishers, 1986.

24 Fletcher RH, Fletcher SW, Wagner EH. Clinical epidemiolFletcher RH, Fletcher SW, Wagner EH. Clinice
ogy. Baltimore: Williams and Wilkins, 1996.

25 Sackett DL, Haynes RB, Guyatt GH, Tugwell P. Clinical epidemiology. A basic science for clinical medicine. Boston: Little, Brown and Co, 1991.

26 Last JM. A dictionary of epidemiology. New York: Oxford University Press, 1995. 